\title{
Cleidocranial Dysplasia of a 13-year-old Bangladeshi Girl: A Rare Case Report
}

\author{
SN RITA ${ }^{\mathrm{a}}, \mathrm{MM} \mathrm{HASAN}^{\mathrm{b}}, \mathrm{N} \mathrm{AMIN}^{\mathrm{c}}, \mathrm{SMA} \mathrm{SADAT}^{\mathrm{d}}$
}

\begin{abstract}
:
Cleidocranial dysplasia (CCD) is an uncommon autosomal inheritant congenital skeletal defect that primarily affects the bones and teeth, and shows an autosomal inheritance. A 13-year-old Bangladeshi girl presented with delayed eruption of the permanent anterior teeth. She was short-statured, well-oriented young girl with narrow, drooped shoulders, malformed or absent clavicles, brachycephalic head with frontal and parietal bossing, hypoplasticzygomatic bones, bulging calvarium, and depressed nasal bridge with a broad
\end{abstract}

\section{Introduction:}

Cleidocranial dysplasia (CCD) is very uncommon autosomal inheritant congenital skeletal defect that primarily affects the bones and teeth. CCD is characterized by delayed closure of fontanelles, presence of open skull sutures, hypoplastic or aplastic clavicles, supernumerary teeth, delayed eruption of permanent dentition, wide pubic symphysis, short stature and a variety of other skeletal changes. Delayed closure of the anterior

a. Professor Dr. Sufia Nasrin Rita, BDS, FCPS, Head, Department of Orthodontics, Sapporo Dental College and Consultant, Square Hospitals Ltd, Dhaka, Bangladesh

b. Dr. Muhammad Mahdee Hasan, BDS, FCPS, Assistant Professor, Department of Orthodontics, Sapporo Dental College, Dhaka, Bangladesh.

c. Professor Dr. Nurul Amin, BDS, PhD, Head, Department of oral \& maxillofacial surgery, Sapporo Dental College, Dhaka, Bangladesh.

d. Dr. S. M. Anwar Sadat, BDS, MCPS, FCPS, MS, Associate Professor, Department of Oral \& Maxillofacial Surgery, Dhaka Dental College and Consultant, Square Hospitals Ltd, Dhaka, Bangladesh.

Adddress of Correspondence: Professor Dr. Sufia Nasrin Rita, BDS, FCPS (Orthodontics and Dentofacial Orthopedics), Head, Dept of Orthodontics, Sapporo Dental College, Uttara, Dhaka, Bangladesh., Consultant, Square Hospitals Ltd, Dhaka, Bangladesh. E-mail: sufianasrin2007@gmail.com. Cell: +8801711985427 alar base. Intraoral examination revealed persistence of the primary dentition, delayed eruption of the permanent teeth, an Angle class III malocclusion, negative overjet, bilateral posterior crossbite. This rarecase of $C C D$ is so far the first case from Bangladesh to be documented in perspective to dental surgery and orthodontics.

Key Words: Autosomal InheritanceCleidocranial Dysplasia, Delayed Eruption,Supernumerary Teeth

(J Bangladesh Coll Phys Surg 2020; 38: 213-217)

DOI: https://doi.org/10.3329/jbcps.v38i4.48982

fontanelle and metopic sutures results in frontal bossing ${ }^{1-3}$.

The different clinical manifestations reflect the basic mechanisms of skeletal development, patterning, bone and cartilage formation, growth and homeostasis ${ }^{4}$. The oral manifestations of CCD include an underdeveloped maxilla with a high, narrow arched palate, prolonged retention of deciduous teeth, failure of the secondary dentition to erupt, delayed maturation among the permanent teeth and multiple impacted supernumerary teeth. ${ }^{1,5-7}$

The incidence of CCD is one per million births. It affects men and women with equal frequency. CCD appears spontaneously with no apparent genetic cause in approximately $40 \%$ of affected patients, and one in three patients has unaffected parents ${ }^{6,8}$. We herein report a case of CCD of a 13-year-old Bangladeshi girl\& probably the first case from Bangladesh to be documented in perspective to dental surgery and orthodontics.

\section{Case Presentation:}

A 13-year-old Bangladeshi girl was referred to the department of orthodontic, Sapporo dental College, Dhaka, Bangladesh by a local dental surgeon. She presented with her mother with the chief complaint of delayed eruption of thepermanent anterior teeth. Retained anterior deciduous teeth were carious \& looked ugly that's why she was often teased at school. Her smile was very unpleasant, which resulted in 
difficulty communicating with her classmates. Failed eruption of her permanent teeth was the reason that the patient sought treatment. Her parents reported an unremarkable medical history. She was in good health with no medications and no known allergies. She had no history of trauma to the mouth, teeth, or jaws.

A general physical examination revealed a shortstatured, well-oriented young girl with narrow, drooped shoulders (Figure-1). Further examination showed an abnormal facility in opposing her shoulders (Figure 2) due to malformed or absent clavicles, which was later confirmed with a small malformed clavicle in chest radiograph (Figure 3). Facial examination showed a brachycephalic head with frontal and parietal bossing, hypoplasticzygomatic bones, bulging calvarium, and depressed nasal bridge with a broad alar base (Figure 2). Intraoral examination revealed persistence of the primary dentition, delayed eruption of the permanent teeth, an Angle class III malocclusion, negative overjet, bilateral posterior crossbite (Figure 4).

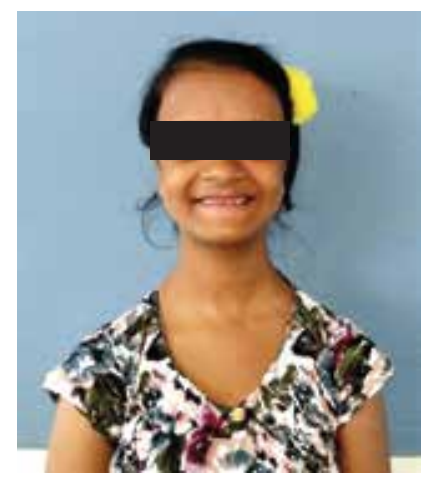

Figure 1: Frontal view shows narrow \& dropped shoulders, smile shows retained carious upper anterior teeth resulting unpleasant smile.

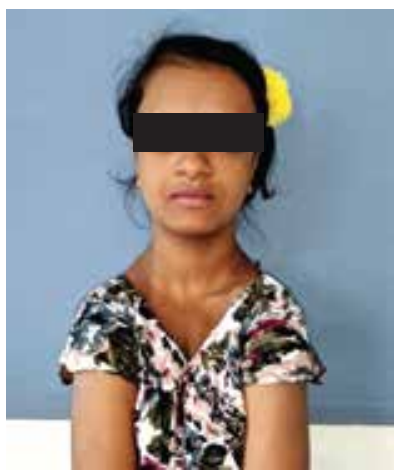

Figure 2: Close approximation of her shoulders in front of the chest

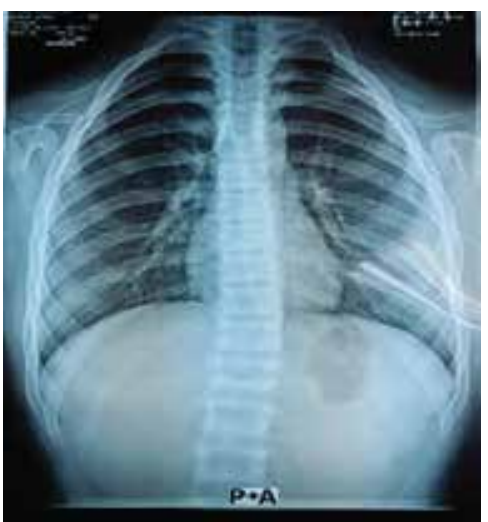

Figure 3: X-ray Chest P/A view shows malformed small clavicle.
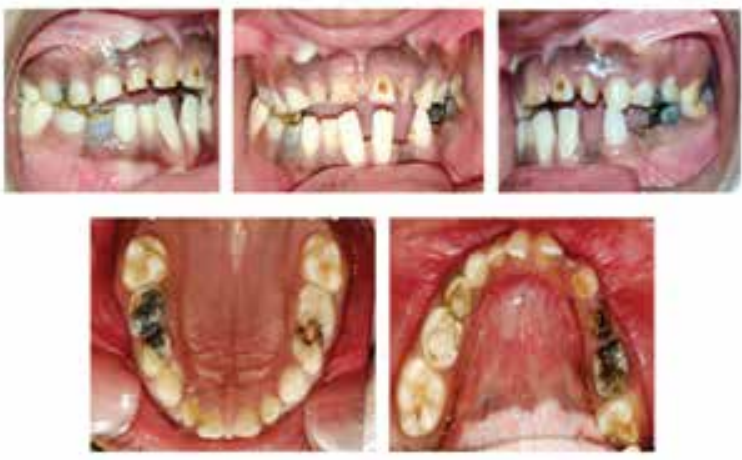

Figure 4: Intra-oral photograph shows bilateral crossbite, multiple retained deciduous teeth with caries.

A CBCT \& panoramic X-ray show the presence of multiple supernumerary teeth in both jaw which are 16 in number; 3 in both side of upper jaw, 6 in lower left side \& 4 in lower right side (Figure 5-7), impaction of the most maxillary \& mandibular permanent teeth, ectopic position of upper left $2^{\text {nd }}$ premolar, dilacerations of lower left $2^{\text {nd }}$ molar and caries in several deciduous teeth. The anterior-posterior (Figure 8) and lateral cephalogram (Figure 9) show open sutures of the skull, large fontanelles, small maxillary sinuses, and a prognathic mandible. The cephalometric analysis confirmed the class III skeletal Malocclusion. The anterior and posterior cranial base are significantly reduce. Increased horizontal mandibular growth is found along with anterior rotation of the mandible in relation to the cranial base. The chest radiograph shows a very narrow thorax with oblique ribs and hypoplastic clavicles (Figure 3 ). 
Written consent was taken from patient's guardian to publish her disease features and photographs.

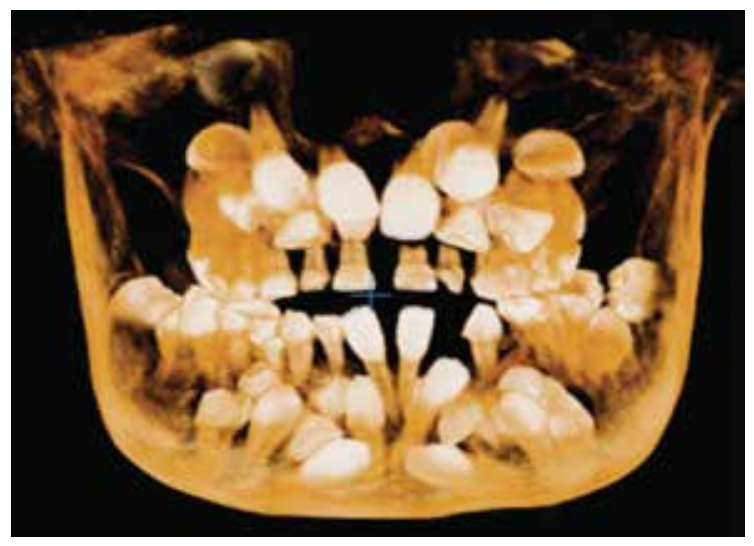

Figure 5: $\mathrm{CBCT}$ frontal view shows multiple impacted teeth.

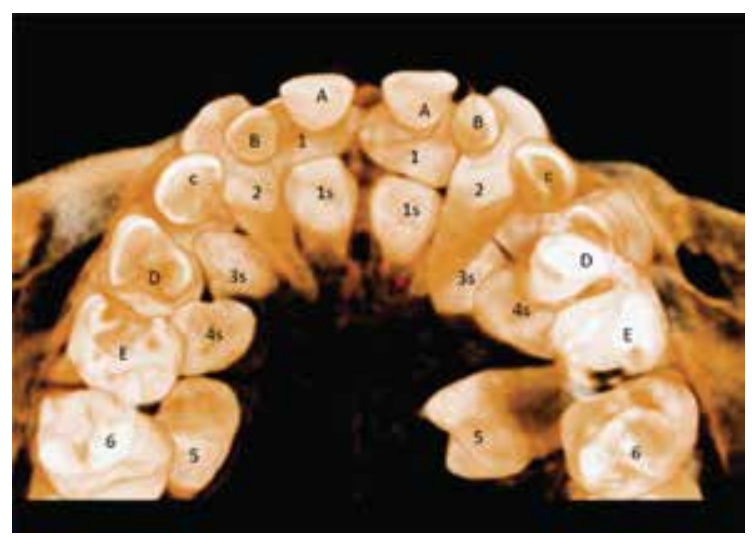

Figure 6: CBCT occluso-palatal view shows numerous supernumerary teeth which causes impaction of multiple permanent tooth.

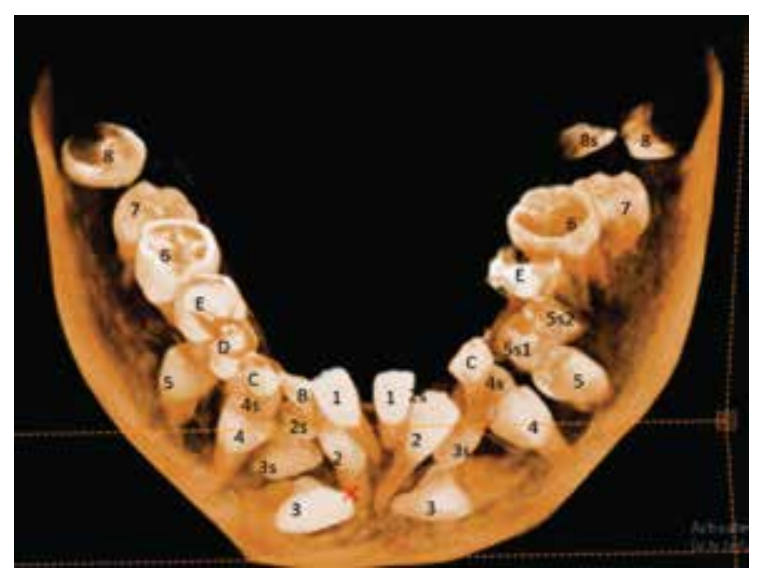

Figure 7: CBCT occluso-baccal view shows multiple supernumerary teeth which causes impaction of permanent teeth.

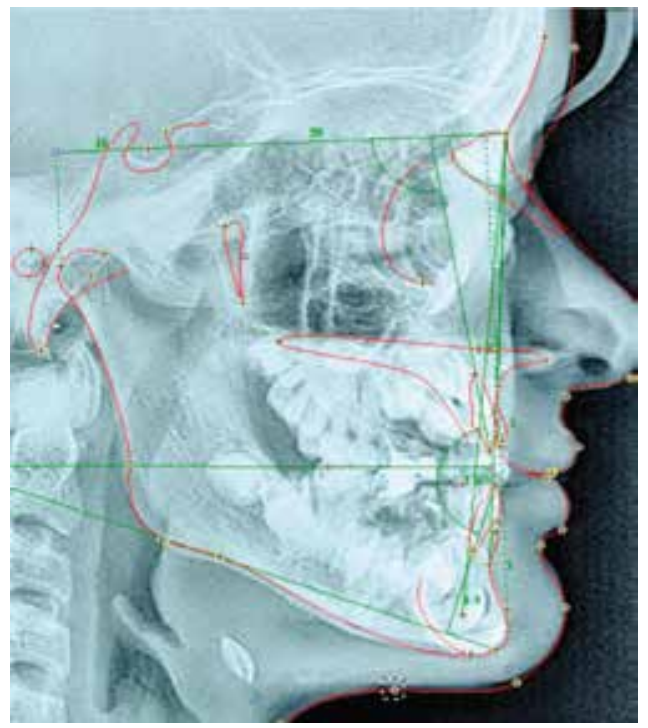

Figure 8 X-ray Lateral Cephalogram shows normal maxilla with prognathic mandible.

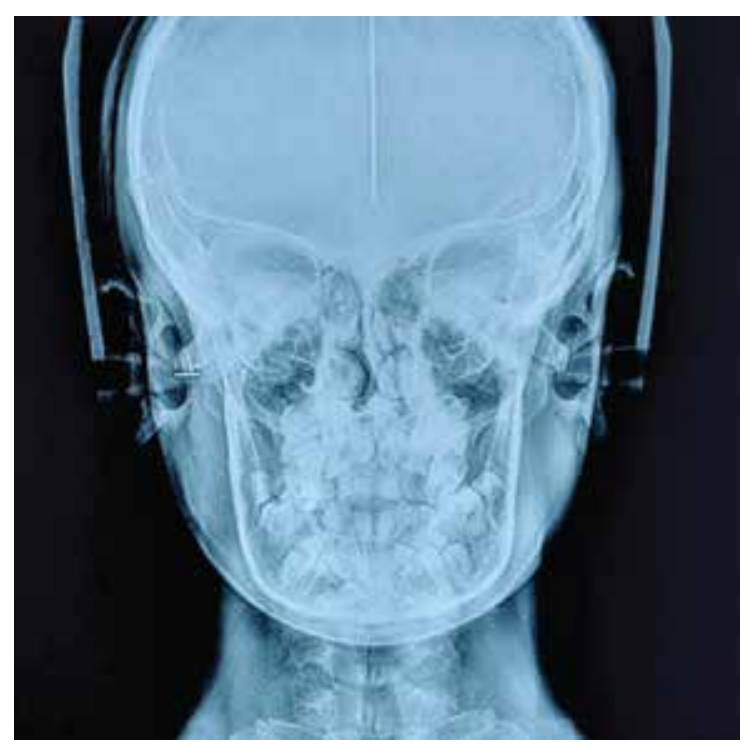

Figure 9: X-ray Frontal cephalogram shows bulging calvarium, narrow maxilla.

\section{Discussion:}

CCD is diagnosed by the clinical and radiological findings. The clinical findings of $\mathrm{CCD}$, although present at birth, could be easily missed because of their extremely low frequency, rare manifestation of the typical extraoral symptoms in early childhood, and the clinical variety of the disorder ${ }^{3}$, as was true in the present case.

A characteristic feature of CCD is aplastic or hypoplastic clavicleswhich is responsible for the 
appearance of narrow, drooped shoulders and for the wide range of shoulder movement, resulting in the ability of the patient to approximate his or her shoulders in front of the chest ${ }^{2,9,10}$. This ability is not always recognized by the patient, as is true in the present case.

The skull base is dysplastic with reduced growth, resulting in increased skull width and leading to brachycephaly and hypertelorism that are usually associated with frontal and parietal bone bossing ${ }^{2}$. The present case had the similar feature.

Midface deficiency; underdeveloped paranasal sinuses; hypoplastic maxillary, nasal, and zygomatic bones; recession of the nasal bridge; a wide alar base; and prominent frontal, parietal, and occipital bones are common findings in patients with CCD. The underdeveloped maxilla with overall deficient growth of the midface combined with the direction of mandibular condylar growth and its anterior rotation give the impression of relative or actual mandibular prognathism 2, 11, 12. In the present case, the cephalometric analysis shows normal growth of the midface but mandible is prognathic, resulting in a skeletal class III malocclusion.

Dental abnormalities are typical main features of CCD, and they occur in $93.5 \%$ of affected patients ${ }^{6}$. The primary dentition usually develops relatively normally [13], while the permanent dentition is severely disturbed. Presence of supernumerary teeth, prolonged retention of the primary dentition, failed eruption of the permanent teeth, multiple crown and root abnormalities, crypt formation around impacted teeth, and ectopic locations of teeth are the more common dentition disturbances ${ }^{9,14}$. A high arched palate is a less common oral manifestation of CCD. In the present case, failed eruption of the permanent teeth was the reason that the patient sought treatment. She presented with multiple supernumerary teeth that impeded normal eruption of the permanent teeth.

Other features seen in CCD are deformities of the thoracic region, pelvic and pubic bones, and fingers. More specifically, finger abnormalities include short, tapered fingers and anomalies of the phalangeal, tarsal, metatarsal, carpal, and metacarpal bones $7,9,15,16$.

CCD is highly polymorphic; therefore, absolute verification of the diagnosis of CCD can only be obtained by molecular genetic analysis ${ }^{1-3}$. This patient had not been previously diagnosed, a molecular genetic analysis was proposed. The patient's parents declined molecular genetic analysis for personal reasons; therefore, identification of the responsible gene was not possible.

The successful treatment of patients with CCD requires a team approach and compliance of patient. An interdisciplinary treatment approach involving orthodontics, maxillofacial surgery, prosthodontics, pediatrics, neuropediatrics, ophthalmology, and orthopedics is obligatory ${ }^{17}$. Genetic counseling for family planning should certainly be advised. Good collaboration among the specialists, the patient, and the patient's family is essential for an organized treatment approach in which each member can contribute his or her expertise for the best treatment outcome ${ }^{1,10}$. The overall treatment goal is to establish functional occlusion and an aesthetic facial and dental appearance. Sometimes this disorder causes psychological problems for the patients; therefore, proper motivation and support are important.

\section{Conclusion:}

Clinician would be highly benefited by the knowledge of the clinical characteristics, family history, and diagnostic tools for CCD, that enable them to achieve an early diagnosis and implement appropriate treatment to improve function and aesthetics.

\section{Reference:}

1. Kolokitha OE, Papadopoulou AK: Cleidocranial dysplasia: Etiology, clinical characteristics, diagnostic information and treatment approach. Hell Orthod Rev. 2008, 11:21-33.

2. Golan I, Baumert U, Hrala BP, Müssig D: Dentomaxillofacial variability of cleidocranial dysplasia: Clinicoradiological presentation of systemic review. J Dentomaxillofac Radiol. 2003, 32: 347-354. https://doi.org/10.1259/dmfr/ 63490079. PMid:15070835

3. Golan I, Baumert U, Hrala BP, MubigD: Early craniofacial signs of cleidocranial dysplasia. Int J Pediatr Dent. 2004, 14: 49-53.https://doi.org/10.1111/j.1365-263X. 2004. 00501. xPMid:14706028

4. Mundlos S et al. Cleidocranial dysplasia: clinical and molecular genetics. J Med Genet. 1999 Mar;36(3): 177-182.

5. Shaikh R, Shusterman S. Delayed dental maturation in cleidocranial dysplasia. ASDC J Dent Child. 1988 Sep-Oct;65(5):325-329. 
6. McNamara CM, O' Riordan BC, Blake M, Sandy JR. Cleidocranial dysplasia: radiological appearances on dental panoramic radiology. DentomaxillofacRadiol. 1999 Mar;28(2):89-97. https://doi.org/10.1038/sj.dmfr. 4600417.PMid:10522197

7. Jensen BL, Kreiborg S. Craniofacial abnormalities in 52 schoolage and adult patients with cleidocranial dysplasia. J Craniofac Genet Dev Biol. 1993 Apr-Jun;13(2):98-108.

8. Tanaka JLO, Ono E, Filho EM, Castilho JCM, Moraes LC, Moraes MEL:Cleidocranial dysplasia: importance of radographic images in diagnosis of the condition. J Oral Sci. 2006, 48: 161-166. https://doi.org/10.2334/josnusd. 48.161.PMid: 17023750

9. Suba Z, Balaton G, Gyulai-Gaal S, Balaton P, Barabas J, Tarjan I: Cleidocranialdyspasia: diagnostic criteria and combined treatment. J Craniofac Surg. 2005, 16: 1122-1126. https://doi.org/10.1097/01.scs.0000179747.75918.58. PMid: 16327567

10. Chelvan HT, Malathi N, Kailasam V, Ponnudurai A: Cleidocranial dysplasia: A Family report. J Indian SocPedodPrev Dent. 2009, 27: 249-252. https://doi.org/ 10.4103/0970-4388.57661.PMid:19915277

11. Jensen BL, Kreiborg S: Craniofacial growth in cleidocranialdysplaia- a roentgencephalometric study. J Craniofac Genet Dev Biol. 1995, 15: 35-43.
12. Kreiborg S, Jensen BL, Larsen P, Schleidt DT, Darvann $\mathrm{T}$ : Anomalies of craniofacial skeleton and teeth in cleidocranial dysplasia. J Craniofac Genet Dev Biol. 1999, 19: 75-79.

13. Jensen BL, Kreiborg S: Development of the dentition in cleidocranial dysplasia. J Oral Pathol Med. 1990, 19: 89-93.https://doi.org/10.1111/j.1600-0714.1990.tb00803. xPMid:2341976

14. Modgil R, Arora KS, Sharma A, Mohapatra S, Pareek S.Cleidocranial Dysplasia: Presentation of Clinical and Radiological Features of a Rare Syndromic Entity. Mymensingh Medical Journal : MMJ, 2018, 27(2):424-428.

15. Garg RK, Agrawal P: Clinical spectrum of cleidocranial dysplasia: a case report. Cases J. 2008, 1: 377. https://doi.org/10.1186/1757-1626-1-377.PMid:1906371 7 PMCid:PMC2614945

16. Mohan RP, Suma GN, Vashishth S, Goel S: Cleidocranial dysplasia: clinicoradiological illustration of a rare case. J Oral Sci. 2010, 52: 161-166. doi: 10.2334/josnusd.52.161. https://doi.org/10.2334/josnusd.52.161.PMid:20339249

17. Almeida LCA, Lima FBF, Matushita H, Valença MM,Castro TLF, Mendonça RN. Cleidocranial dysplasia, a rare skeletal disorder with failure of the cranial closure: case-based update. Child's Nervous System(2020). doi: org/10.1007/s00381-020-04831-z. 